\title{
Factor Analysis of Machining Parameters On Surface Integrity of CFRP Composites Based On A Microscopic Finite Element Cutting Model
}

Jianzhang Xiao ( $\nabla$ xiaojz@zju.edu.cn )

Zhejiang University

Guifeng Wang

Zhejiang University

Hang Su

Zhejiang University

Pengcheng Huang

Zhejiang University

Zhongzhe Chen

Zhejiang University

\section{Research Article}

Keywords: Carbon fiber-reinforced polymer (CFRP) composites, Surface integrity, Microscopic finite element cutting model, Factor analysis, Machining parameters

Posted Date: July 15th, 2021

DOI: https://doi.org/10.21203/rs.3.rs-697702/v1

License: (c) (i) This work is licensed under a Creative Commons Attribution 4.0 International License. Read Full License 


\title{
Factor analysis of machining parameters on surface integrity of CFRP composites based on a microscopic finite element cutting model
}

\author{
Jianzhang Xiao ${ }^{1,2^{*}}$, Guifeng Wang ${ }^{1}$, Hang Su ${ }^{2}$, Pengcheng Huang ${ }^{1}$, Zhongzhe Chen ${ }^{1}$ \\ ${ }^{1}$ College of Mechanical and Electrical Engineering, Jinhua polytechnic, Jinhua, China \\ ${ }^{2}$ Science and Technology Development Center of Ministry of Education, Beijing, China
}

\begin{abstract}
In the paper, a three-dimensional (3D) micromechanical finite element (FE) cutting model with three phases was developed to study the surface integrity of CFRP composites. The surface roughness and the depth of subsurface damage were predicted
\end{abstract} by using the FE cutting model, which were used to characterize the surface integrity. The machined surface observations and surface roughness measurements of CFRP composites at different fiber orientations were also performed for model validation. It is indicated that the 3D micromechanical model is capable of precisely predicting the surface integrity of CFRP composites. To investigate the complex coupling influences of multiple machining parameters on the surface integrity, the factor analysis of multiple machining parameters was performed, and then the effects of these machining parameters on the surface roughness and subsurface damage depth were obtained quantitatively. It was found that the fiber orientation angle and cutting speed are the most significant factors affecting the surface roughness, and the fiber orientation and edge radius are the main factors affecting the subsurface damage depth. The results also reveal that coupling effects of depth of cut and edge radius should be considered for 
improving the surface integrity of CFRP composites.

Keywords Carbon fiber-reinforced polymer (CFRP) composites; Surface integrity; Microscopic finite element cutting model; Factor analysis; Machining parameters

\section{Introduction}

Carbon fiber-reinforced polymer (CFRP) composites with high strength, light weight and fatigue and corrosion resistances, which consist of various polymer matrices and fibers. Owing to their excellent mechanical properties, CFRP composites are becoming the promising solutions to various industrial applications, especially used as structural components in the weight-critical aerospace industry [1, 2]. Despite the fact that composite parts are fabricated near-net shape, machining operations such as trimming and drilling are still required in order to achieve close fit tolerances and finalize part sizes. The surface integrity of a machined component after such machining operations needs to be investigated for assembly purpose, which including surface roughness, subsurface damage and residual stresses [3, 4]. Considering the surface integrity has an important effect on the performance of the structural parts, it is of great technological and practical interest to study the surface integrity in machining CFRP composites.

Workpiece surface integrity and functional performance of CFRP composites have been the focus of a great many publications over the last decade. Significant efforts were made to investigate the quality of the machined surface in terms of surface topography as well as the subsurface layer. Çolak et al. [5] measured the 3D surface 
topography of a machined CFRP surface and evaluated the influences of fiber orientation on the surface quality. Pecat et al. [6], Rajasekaran et al. [7], Schorník et al. [8], Lissek et al. [9] and Abhishek et al. [10] studied the influence of cutting parameters on the surface quality of CFRP by using an experimental approach. Konneh et al. [11], Haddad et al. [12] and Voß et al. [13] investigated the surface damage on the machined surface under various tool geometries and cutting parameters. To examine the detail information of subsurface damage, various experimental observation technologies have been used, such as the application of the optical and electron microscopy techniques [14-16]. On the other hand, as the development of modeling tools, prediction of machining-induced damage in composite cutting has been commonly achieved using finite element method (FEM). Wang et al. [17] studied the influences of machining parameters on surface subsurface damage by using the finite element modeling in CFRP cutting. Ghafarizadeh et al. [18] built a finite element model to investigate the machining damage and chip formation mechanism for the flat end milling of unidirectional CFRP. Zenia et al. [19, 20] proposed a finite element model for the prediction of machining damage under the machined surface. Calzada et al. [21] developed a microstructure-based finite element model for CFRP machining to describe the fiber failure mode in the chip formation process. Although the subsurface damage in composite cutting have been analyzed with the simulation tools, the detail information of microstructure influences the machined damage has been neglected as well as the surface topography in these models.

The surface integrity can be investigated by using the experimental tests, however, 
the research on CFRP composites machining is not only expensive and time-consuming, but also the carbon chips are dangerous for human health. In addition, there still is a big challenge to obtain the good surface integrity of CFRP composites under different cutting conditions. The present work is devoted to develop a $3 \mathrm{D}$ micromechanical $\mathrm{FE}$ model with considering the microstructure to study the surface integrity of CFRP composites. Based on the simulation results, the surface integrity can be characterized by the surface roughness and subsurface damage depth. The multi-factor analysis is further done to study the effect of multiple machining parameters on the surface integrity of CFRP composites, so as to determine the most important machining parameters and give a quantitative comparison of their influences. At the same time, the observations and roughness measurements of the machined surfaces at different fiber orientations were also performed for the validation of the FE model.

\section{Experiment setup of CFRP composites trimming}

The CFRP composites used in our tests were fabricated from the IMS/X850 prepregs with T800 carbon fiber of $65 \%$. Four types of unidirectional laminae with $6 \mathrm{~mm}$ of thickness were selected in the experiments, in which the fiber orientations are $0^{\circ}, 45^{\circ}$, $90^{\circ}$ and $135^{\circ}$, respectively. The experimental setup and the geometry feature of the cutting tool are shown in Fig. 1. The milling process was performed by using a diamond coated and cemented carbide multi-edge milling cutter with a $10 \mathrm{~mm}$ diameter, $36 \mathrm{~mm}$ cutting length, 12 teeth and $15^{\circ}$ helix angle. The workpiece was fixed by the fixture mounted on a Kistler 9272 dynamometer, which was used to measure the cutting force. 
The machining conditions which cutting speed is $157 \mathrm{~m} / \mathrm{min}$, radial depth of cut is 1 $\mathrm{mm}$ and axial depth of cut is $6 \mathrm{~mm}$. To evaluate the machined surface quality of the workpiece samples after milling experiment, the machined surfaces were observed by a Hitachi S-3400N scanning electron microscope (SEM). And then the machined surface roughness of the composite workpiece was measured by MAHR-Perthometer M1 instrument. Each measurement was repeated five times and the average value was taken as the effective one.

\section{FE modelling of CFRP composites}

\subsection{Description of 3D cutting FE model}

Considering the microstructure of three individual phases (i.e., fiber, matrix and the interphase between the fiber and matrix) of the CFRP composites, a 3D micromechanical finite element cutting model was established for CFRP composites, as shown in Fig. 2. The orthogonal cutting simulation was carried out by using the explicit module of the general finite element software ABAQUS/Explicit. The tool was assumed to be a rigid body. The nose radius of the tool is $5 \mu \mathrm{m}$ and the rake and relief angles are $25^{\circ}$ and $10^{\circ}$, respectively. The tool was given a constant cutting velocity in the $x$ direction during the cutting process, the movement of which in the $y$ direction was constrained in the model. The size of model was adopted as $215 \times 215 \times 50 \mu \mathrm{m}$. The model was meshed with 8-node brick elements with reduced integration (C3D8R) and there are about 100,000 elements with a minimum element length of $0.5 \mu \mathrm{m}$ along the cutting path. The displacements were constrained in three directions $(x, y$ and $z)$ at the 
bottom surface of the model and the longitudinal displacement $\left(U_{y}\right)$ was restricted at the left-hand surface of the model. The fiber in the composite model has a hexagonal array arrangement based on the actual measurement. The fiber orientation angle $\theta$ was defined relative to the cutting path in a clockwise direction. The thickness of interphase was evaluated as $0.5 \mu \mathrm{m}$ based on the fiber diameter. A kinematical contact definition was applied between the tool surface and workpiece based on the penalty-function principle. A self-contact condition was adopted for each phase of the composites to avoid penetration among deleted elements during cutting process.

The friction between the cutting tool and fiber plays an important role in the machining of composites. The Coulomb friction law is applied to various contact surfaces. The coefficient of friction at the tool and chip interface in the present micromechanical model was taken as $0.68,0.84,0.63$, and 0.96 for the $0^{\circ}, 45^{\circ}, 90^{\circ}$ and $135^{\circ}$ fiber orientations, which was based on the orthogonal machining tests [22], respectively. The material properties of the fiber and matrix provided by $[2,23]$ were given in Table 1.

\subsection{Material modelling}

1) Fiber and matrix models

The 3D micromechanical cutting model was built with consideration of the three constituents of the CFRP composites, i.e., fiber, interphase and matrix. The carbon fiber is assumed to be an elastic and anisotropic material and can be fully characterized by the anisotropic elasticity moduli of the fiber $\left(E_{f}\right)$. It has been observed that the carbon fiber has not significant plasticity before failure. Therefore, the carbon fiber is assumed 
to fail at the onset of the stress of the fiber exceeding the maximum stress in either tension or shear, i.e., the element will be immediately deleted when the stress reaches the ultimate strength of fiber.

The epoxy matrix of the composite is modeled as an isotropic and elasto-plastic material, the elastic behavior of which is characterized by the elastic modulus $\left(E_{m}\right)$ and the Poisson ratio $\left(v_{m}\right)$ and the plastic behavior is described by von Mises yield criterion and isotopic hardening. The damage is assumed to occur when the stress reaches the ultimate tensile or compressive strength of matrix.

2) Interphase model with damage failure

The interphase is defined as a transversely isotropic materials (the elastic modulus is denoted by $E_{i}$ ). A progressive damage happens at the maximum normal and tangential stress $\left(\sigma_{\max }\right.$ and $\left.\tau_{\max }\right)$. The normal damage behavior of the interfacial elements is modeled with a tensile progressive damage model, which describes the normal separation of the interface. After damage initiation occurs, the degree of damage can be fully characterized by a scalar damage variable $\left(d_{i}\right)$. As the normal strain increases, the current state of damage exhibits itself in the form of a decrease modulus of elasticity ( $\left.E_{i}^{d}\right)$ as shown below:

$$
E_{i}^{d}=\left(1-d_{i}\right) E_{i}
$$

where $E_{i}^{d}$ is the damaged elastic modulus of interphase. The material stiffness is equal to zero when the damage variable is equal to unity which means that the material fully reaches fracture. The damage variable is then said to linearly evolve according to: 


$$
d_{i}=\frac{L_{e}}{u_{f}^{p l}} \bar{\varepsilon}^{p l}
$$

where $L_{e}$ is the characteristic element length, $\bar{\varepsilon}^{p l}$ is the equivalent plastic strain and $u_{f}^{p l}$ is the equivalent plastic displacement at failure which is expressed as

$$
u_{f}^{p l}=\frac{2 G^{f}}{\sigma_{y}}
$$

where $G^{f}$ is the fracture energy of the material, and $\sigma_{y}$ is the static yield stress before the initiation of damage.

\section{4 surface integrity analysis and validation}

Surface integrity plays a predominant role in determining the machining accuracy of CFRP composites, which is resulted from material removal with the combination of bending, crushing and shearing, and depends on the cutting condition. In the present work, a simulation investigation was carried out to study the surface integrity of CFRP composites, in which the surface roughness and subsurface damage depth were analyzed.

\subsection{Surface roughness analysis}

The comparisons of the simulated and experimental results of machined surface of CFRP at $\theta=0^{\circ}$ were presented in Fig. 3, in which the material and cutting conditions adopted in FE simulation were the same as those used in the tests (Table 1). The fibers on the machined surface are laid in parallel to the cutting direction (see Fig. 3a and c), and two different material fracture mechanism occurs for the fiber orientation of $0^{\circ}$, in which the crushing-dominated failure happens in the tool-fiber contact zone and the 
bending-dominated failure occurs beyond the cutting zone. To characterize the surface roughness, the machined surface profile was then numerically distinguished according to FE results, as shown in Fig. 3b. The arithmetical mean surface was regarded as a reference surface, and the arithmetic mean of the departures of roughness profile was further obtained to evaluate the machined surface roughness $R_{a}$. The fibers were only cracked and peeled off along the trimming path, and cause the machined surface smoothly. As shown the experimental observation in Fig. 3d, the machined surface is mainly composed of bare fibers and resin ridges at $0^{\circ}$, which is consistent with the simulation results (Fig. 3c).

For the case of $45^{\circ}$, the crushing governs the fracture of the fibers become a more dominated mechanism $[24,25]$, as shown in Fig. 4. It can be seen that most of the fibers fractured quickly due to the high stress concentration in the tool-fiber contact zoon. As a result, a machined surface with wave fracture shape was obtained, as shown in Fig. 3a and $\mathrm{c}$. The machined surface is relatively smooth at the $45^{\circ}$ fiber orientation, and the debonding between fiber and matrix can be found in the surface, which is caused by the failure of interphase. The measurement of machined surface is mainly composed of coated resin, and low damage is found on the surface at $45^{\circ}$ which also match well with the simulation, as shown in Fig. 4 d.

For the case of $90^{\circ}$ (Fig. 5), the fiber fracture mechanism is more complex: the crushing-dominated failure and the bending-dominated failure are occurring at the same time. It can be seen that most of the fibers are sheared and bended, which induced a machined surface with transverse fracture, as shown in Fig. 5a and c. The depth of the 
interphase debonding and fiber fracture increases by comparing with the result at $45^{\circ}$, as shown in Fig. 5b. Some small pitting damages were found in the observation of $90^{\circ}$, which are the ends of carbon fiber bundles on the machined surface, and in good agreement with the simulations, as shown in Fig. 5 d.

Fig. 6 shows the simulation result of machined surface in cutting CFRP composite at $\theta=135^{\circ}$. Due to the bending-dominated fiber failure in the cutting case of $135^{\circ}$, large fragment formed ahead of the cutting edge, which leads to most of the fibers fracture under the cutting surface. It can be seen that a poor machined surface with large subsurface damage is obtained at $135^{\circ}$, as shown in Fig. 6 a and c. In addition, a bouncing back of fiber was observed in simulation, which causes brushing between the relief surface of tool and the machined surface, as shown in Fig. 6b. From the Fig. 6d, the damage such as big pits of carbon fiber bundles and resin ridges were obviously observed at $135^{\circ}$, which is also consistent with the simulation results.

The surface roughness from simulations and experiments in the cutting of CFRP are presented in Fig. 7. It is indicated from the figure that the simulation predictions match well with the measured values of surface roughness at different fiber orientation angles. The surface roughness is greatly influenced by the fiber orientations, which increases with increasing the fiber orientation, and the surface roughness is minimum at $0^{\circ}$ while maximum at $135^{\circ}$. There is a variation between the measured roughness and the simulation prediction at $0^{\circ}$, because the fibers and matrix fragments often adhere to the surface in experiment. To further understand the surface topography, a cross-sectional examination of the finished workpiece is performed in next section. 


\subsection{Subsurface damage analysis}

To further clarify the surface topography, the subsurface layer was investigated by observing the cross-sections of the machined surface. Fig. 8 shows the numerical depths of the subsurface damage, which reveal that the damage layer on the machined surface is dependent on the fiber orientation. It is shown from the figure that the experimental depths of subsurface damage $\left(L_{d}\right)$ are in good agreement with the predictions by the FE modelling, as shown in Fig. 9. When the fiber orientation was $135^{\circ}$ (Fig. 8d), fiber fracture was dominated by fiber bending as the tool ploughed into the workpiece and formed deepest damage in subsurface layer with $40 \mu \mathrm{m}$. These subsurface damages decreased to $29 \mu \mathrm{m}$ as the fiber orientation decreased to $90^{\circ}$ (Fig. 8c). When the fiber orientation was $45^{\circ}$, the subsurface damage significantly decreased to $18 \mu \mathrm{m}$ with mic-cracks caused by the crushing-dominated fracture. At the fiber orientation of $0^{\circ}$, the minimum damage depth was found, which was $11 \mu \mathrm{m}$ in simulated cutting, respectively.

\section{Factor analysis of multiple parameters on surface integrity}

It is well known that the surface integrity of CFRP composites is affected by many factors during the machining process. To provide a better understanding of the optimized machining quality, the significance of multiple machining parameters was studied based on the statistical method. By using the approach of factor analysis, the dominant machining parameters and coupling of double parameters affecting the surface roughness and subsurface damage depth were determined by quantitative comparison. 


\subsection{Implementation of factor analysis}

Factor analysis is a mathematical statistics method used to study whether one or more control variables of different levels has a significant effect on the observed variable. And factorial experiments need be done to provide basic data for factor analysis. The precise evaluation of the main effects and interactions of various factors may be acquired by full factorial experiments, but it needs a large number of experimental data with expending lots of time and cost. Therefore, fractional factorial experiments are generally adopted to obtain a few key factors by requiring fewer experimental data. In this study, the two-level fractional factor analysis is adopted and implemented based on FE simulation results, which can be expressed as $2_{R}^{k-p}$ (here $k$ is the number of factors; $p$ is the number of full factorial experiments dichotomized; $R$ is the resolution level). According to the FE cutting simulation of CFRP composite as presented in the above section, a fractional factorial experiment of $2_{I I I}^{6-3}$ was finally taken to analyze the effects of six factors (i.e., fiber orientation angle, fiber volume fraction, cutting speed, depth of cut, rake angle and edge radius) on the machined surface integrity.

The different levels of machining parameters used in factor analysis are shown in Table 2. The cases of fractional factorial experiment design are shown in Table 3, in which the central value of each factor is given to check the nonlinearity in the influencing relationship of each factor, and four such same cases are included to reflect the discretion error of factorial simulation cases. 


\subsection{Results of multi-factor analysis}

In this paper, a series of simulations were performed to provide the sample data needed in the factor analysis, so as to investigate the effects of machining parameters and coupling of double parameters on the surface roughness and subsurface damage depth. The factor analysis is performed by the Minitab software, in which the confidence level of $95 \%$ was used, i.e., the critical $\mathrm{P}$ value is 0.05 .

The main effects of single machining parameters on the surface roughness were obtained, as presented in Fig. 10. It can be seen from Fig. 10b that the surface roughness gradually decreases with the increase of cutting speed, and this decreasing trend exists for all the fiber orientations. While the surface roughness increases with the increase of the other machining parameters in the studied range. It is known that the surface roughness increases with fiber orientation from $45^{\circ}$ to $135^{\circ}$, as shown in Fig. 10a. A linearly increase in surface roughness was found when the depth of cut increases from 30 to $70 \mu \mathrm{m}$ (Fig. 10c), which implies that larger depth of cut is not preferred for higher surface quality in machining CFRP composite. These simulated results are in good agreement with the results in experiment $[26,27]$. In addition, the specific relationships of the surface roughness and the other three factors are presented in Fig. 10d, e and f, respectively. It is revealed that the effect of the three factors on the surface roughness is approximately linear, this indicates that high value of fiber volume fraction, rake angle and edge radius may not good for improving the surface quality.

The quantitative comparison of multiple machining parameters and their coupling effects on the surface roughness was obtained, as shown in Fig. 11. The results of 
multi-factor analysis of variance for surface roughness are listed in Table 4. It was found that fiber orientation angle $(\theta)$ and cutting speed $\left(V_{c}\right)$ are the most significant factors affect the surface roughness. The depth of cut and edge radius are the next significant factors. Furthermore, the coupling effect of fiber orientation and cutting speed is more significant than the other interactions. It may be concluded that the surface roughness becomes low with the lower value of fiber orientation particularly with the higher cutting speed.

At the same time, the main effects of single factor on the subsurface damage depth were also obtained, as shown in Fig. 12. It can be known that the results of the maximum subsurface damage depth are observed at $135^{\circ}$ while the lowest subsurface damage depth at $45^{\circ}$ as shown in Fig. 11a, and the subsurface damage depth is almost linearly increasing with the edge radius in Fig. 12b. It is found from Fig. 12e that the subsurface damage depth decreases with increasing cutting speed, which indicates that the higher cutting speed is good for machined surface of CFRP. These results are in good agreement with the observed trend in different studies which deal with the subsurface damage $[15,17,20,28]$. Moreover, the relations of subsurface damage depth versus the fiber volume, depth of cut and rake angle were plotted in Fig. 12c, d and f. It is showed that the effect of the three factors on the subsurface damage depth is also approximately linear, this indicates that high value of fiber volume fraction, rake angle and depth of cut may not prefer for higher surface quality.

As shown in Fig. 13, the quantitative comparison of multiple machining parameters and their coupling effects on the subsurface damage depth was presented. The results of 
multi-factor analysis of variance for subsurface damage depth are given in Table 5. The fiber orientation and edge radius are the main factors affecting the response followed by the tool rake angle. Furthermore, a more significant interaction was found between fiber orientation and edge radius, which indicates the subsurface damage depth becomes large with the higher value of fiber orientation couple with edge radius.

\section{Conclusions}

This paper studied the effects of multiple machining parameters on the surface integrity of CFRP composites based on a 3D micromechanical FE cutting model with consideration of the microstructure of composites. The experimental observations of machined surface were carried out for the validation of FE results. And then the factor analysis was used to make a quantitative comparison of the influences of multiple machining parameters. The main conclusions have been summarized as follows:

(1) The proposed FE cutting model of CFRP composites can be used to reliability characterize the surface integrity of machined CFRP composites, in which the surface roughness and subsurface damage depth predicted in the FE simulations show a very good agreement with the experimental results. The cutting model can be further applied to improve the optimal solution of surface integrity of other composites.

(2) It has been noticed that there is significant coupling effect of fiber orientation and cutting speed on the surface roughness, and a more important interaction was found between fiber orientation and edge radius for the depth of subsurface damage. The coupling effects of depth of cut and edge radius should also be considered for improving 
the surface integrity of CFRP composites.

(3) The fiber orientation in the CFRP composites proves to be the most important factor affecting the surface roughness and the subsurface damage depth. The next significant factors are the cutting speed and depth of cut for the surface roughness, while edge radius and rake angle for the subsurface damage depth.

\section{Acknowledgements}

This research work was supported by the Zhejiang Provincial Natural Science Foundation of China (LQ21E050006), the Basic Public Welfare Research Project of Zhejiang Province (LGG19E050010), the Youth Project of Science and Technology Development Center of Ministry of Education (202107), and the Public Welfare Technology Application Projects of Zhejiang Province (LGG18E050022)

\section{Declarations}

\section{a. Conflicts of interest/Competing interests}

The authors declare no competing interests.

\section{b. Availability of data and material}

The raw/processed data required to reproduce these findings cannot be shared at this time as they will be used in an ongoing study.

\section{c. Code availability}

Not applicable (minitab 19 design of experiments "free version").

\section{d. Ethics approval}


This study complies with the ethical standards set out by Springer. All the authors read and approved the final manuscript.

\section{e. Consent to participate}

All the authors consent to participate.

\section{f. Consent for publication}

All the authors consent to publication.

\section{g. Authors' contributions}

All the authors have their contributions on the modelling, experiment measure and data processing.

\section{References}

[1] Golzar M, Poorzeinolabedin M. Prototype fabrication of a composite automobile body based on integrated structure. Int J Adv Manuf Technol 2010; 49(9-12): $1037-1045$

[2] Gao CY, Xiao JZ, Xu JH, Ke YL. Factor analysis of machining parameters of fiber-reinforced polymer composites based on finite element simulation with experimental investigation. Int J Adv Manuf Technol 2016; 83(5-8): 1113-1125.

[3] Jawahir IS, Brinksmeier E, M'Saoubi R, Aspinwall DK, Outeiro JC, Meyer D, Umbrello D, Jayal AD. Surface integrity in material removal processes: Recent advances. CIRP Annals-Manuf Technol 2011; 60(2): 603-626.

[4] Dhieb H, Buijnsters JG, Eddoumy F, Vazquez L, Celis JP. Surface and sub-surface degradation of unidirectional carbon fiber reinforced epoxy composites under dry and 
wet reciprocating sliding. Compos Part A: Appl Sci Manuf 2013; 55: 53-62.

[5] Çolak O, Sunar T. Cutting forces and 3D surface analysis of CFRP milling with PCD cutting tools. Procedia CIRP 2016; 45: 75-78.

[6] Pecat O, Rentsch R, Brinksmeier E. Influence of milling process parameters on the surface integrity of CFRP. Procedia CIRP 2012; 1: 466-470.

[7] Rajasekaran T, Palanikumar K, Arunachalam S. Investigation on the turning parameters for surface roughness using taguchi analysis. Procedia Eng 2013; 51: 781-790.

[8] Schorník V, Dana M, Zetková I. The influence of the cutting conditions on the machined surface quality when the CFRP is machined. Procedia Eng 2015; 100: $1270-1276$.

[9] Lissek F, Tegas J, Kaufeld M. Damage quantification for the machining of CFRP: An introduction about characteristic values considering shape and orientation of drilling-induced delamination. Procedia Eng 2016; 149: 2-16.

[10] Abhishek K, Datta S, Mahapatra SS. Response surface modeling on machining of CFRP composites: effect of process variables on surface roughness, MRR and tool-tip temperature. Int J Mech Eng Res 2013; 3(4): 407-414.

[11] Konneh M, Izman S, Kassim AAR. Milling damage on carbon fibre reinforced polymer using TiAlN coated end mills. J Phys Conf Ser 2015; 628: 12033-12040.

[12] Haddad M, Zitoune R, Eyma F, Castanie B. Study of the surface defects and dust generated during trimming of CFRP: Influence of tool geometry, machining parameters and cutting speed range. Compos Part A: Appl Sci Manuf 2014; 66: 142-154. 
[13] Voß R, Henerichs M, Rupp S, Kuster F, Wegener K. Evaluation of bore exit quality for fibre reinforced plastics including delamination and uncut fibres. CIRP-J Manuf Sci Technol 2016; 12: 56-66.

[14] Davim JP. Surface integrity in machining. NY: Springer; 2010.

[15] $\mathrm{Xu} \mathrm{W,} \mathrm{Zhang} \mathrm{LC.} \mathrm{A} \mathrm{new} \mathrm{approach} \mathrm{to} \mathrm{characterising} \mathrm{the} \mathrm{surface} \mathrm{integrity} \mathrm{of}$ fibre-reinforced polymer composites during cutting. Compos Part A: Appl Sci Manuf 2017; 3: 272-282.

[16] Qian M, Xiao JZ, Wang GF, Huang PC, Chen ZZ, Han GR. Evaluation of heat generation using a microscopic cutting model with thermo-mechanical coupling for CFRP composites. J Reinf Plast Comp 2020; 39(21-22):793-804.

[17] Wang DY, He XD, Xu ZH, Jiao WC, Yang F, Jiang L, Li LL, Liu WB, Wang RG. Study on damage evaluation and machinability of UD-CFRP for the orthogonal cutting operation using scanning acoustic microscopy and the finite element method. Materials 2017; 10(2): 204-223.

[18] Ghafarizadeh S, Chatelain JF, Lebrun G. Finite element analysis of surface milling of carbon fiber-reinforced composites. Int J Adv Manuf Technol 2016; 87(1-4): 1-11.

[19] Zenia S, Ben Ayed L, Nouari M, Delamézière A. Numerical prediction of the chip formation process and induced damage during the machining of carbon/epoxy composites. Int J Mech Sci 2015; 90: 89-101.

[20] Zenia S, Ben Ayed L, Nouari M, Delamézière A. Numerical analysis of the interaction between the cutting forces, induced cutting damage, and machining parameters of CFRP composites. Int J Adv Manuf Technol 2015; 78(1): 465-480. 
[21] Calzada KA, Kapoor SG, DeVor RE, Samuel J, Srivastava AK. Modeling and interpretation of fiber orientation-based failure mechanisms in machining of carbon fiber-reinforced polymer composites. J Manuf Process 2012; 14(2): 141-149.

[22] An QL, Ming WW, Cai XJ, Chen M. Study on the cutting mechanics characteristics of high-strength UD-CFRP laminates based on orthogonal cutting method. Compos Struct 2015; 131: 374-383.

[23] Ghafarizadeh SB, Lebrun G, Chatelain JF. Experimental investigation of the cutting temperature and surface quality during milling of unidirectional carbon fiber reinforced plastic. J Compos Mater 2016; 50(8): 1059-1071.

[24] Xu W, Zhang LC. Effect of tool vibration on chip formation and cutting forces in the machining of fiber-reinforced polymer composites. Mach Sci Technol 2016; 20: $1-18$.

[25] Xu W, Zhang LC. Mechanics of fibre deformation and fracture in vibrationassisted cutting of unidirectional fibre-reinforced polymer composites. Int J Mach Tool Manu 2016; 103: 40-52.

[26] Ramulu M, Wern CW, Garbini JL. Effect of fibre direction on surface roughness measurements of machined graphite/epoxy composite. Compos Manuf 1993; 4(1): $39-51$.

[27] Rajasekaran T, Palanikumar K, Vinayagam BK. Application of fuzzy logic for modeling surface roughness in turning CFRP composites using CBN tool. Prod Eng Res Dev 2011; 5(2): 191-199.

[28] Voß R, Henerichs M, Kuster F, Wegener K. Chip root analysis after machining 
carbon fiber reinforced plastics (CFRP) at different fiber orientations. Procedia CIRP

2014; 14: 217-222.

Table 1 Properties of the three phases used in the cutting simulation of CFRP composite

\begin{tabular}{lll}
\hline Constituents & \multicolumn{1}{c}{ Properties } & Values \\
\hline & Longitudinal elastic modulus, $E_{f 1}(\mathrm{GPa})$ & 294 \\
& Transverse elastic modulus, $E_{f 2}(\mathrm{GPa})$ & 15 \\
& Poisson's ratio, $v_{f 12}$ & 0.3 \\
& Tensile Strength, $X_{f}(\mathrm{GPa})$ & 5.49 \\
Carbon fiber & Shear Strength, $S_{f}(\mathrm{GPa})$ & 0.38 \\
& Diameter, $d_{f}(\mu \mathrm{m})$ & 7 \\
& Fiber volume fraction, $V_{f}(\mu \mathrm{m})$ & $65 \%$ \\
& Density, $\rho_{f}\left(\mathrm{~g} / \mathrm{cm}^{3}\right)$ & 1.81 \\
\hline & Elastic modulus, $E_{m}(\mathrm{GPa})$ & 4 \\
& Poisson's ratio, $v_{m}$ & 0.4 \\
& Tensile Strength, $X_{m}(\mathrm{MPa})$ & 85 \\
& Shear Strength, $S_{m}(\mathrm{MPa})$ & 70 \\
& Density, $\rho_{m}\left(\mathrm{~g} / \mathrm{cm}^{3}\right)$ & 1.26 \\
\hline Epoxy & Longitudinal elastic modulus, $E_{i 1}(\mathrm{GPa})$ & 83.9 \\
& Transverse elastic modulus, $E_{i 2}(\mathrm{GPa})$ & 7.03 \\
& Poisson's ratio, $v_{i 12}$ & 0.37 \\
& Tensile Strength, $X_{i}(\mathrm{MPa})$ & 167.5 \\
& Shear Strength, $S_{i}(\mathrm{MPa})$ & 25 \\
& Thickness, $t_{i}(\mu \mathrm{m})$ & 0.5 \\
& Density, $\rho_{i}\left(\mathrm{~g} / \mathrm{cm}^{3}\right)$ & 1.41 \\
\hline
\end{tabular}

Table 2 The different levels of machining parameters used in factor analysis

\begin{tabular}{ccccc}
\hline Factors & Symbols & Low level (-1) & High level $(+1)$ & Central value (0) \\
\hline Fiber orientation $\left(^{\circ}\right)$ & $\theta$ & 45 & 135 & 90 \\
Fiber volume fraction $(\%)$ & $V_{f}$ & 40 & 80 & 60 \\
Cutting speed (m/min) & $V_{c}$ & 60 & 300 & 180 \\
\hline
\end{tabular}




\begin{tabular}{ccccc}
\hline Depth of cut $(\mu \mathrm{m})$ & $a_{c}$ & 30 & 70 & 50 \\
Rake Angle $\left({ }^{\circ}\right)$ & $\alpha_{t}$ & 5 & 25 & 15 \\
Edge radius $(\mu \mathrm{m})$ & $r_{t}$ & 1 & 20 & 10 \\
\hline
\end{tabular}

Table 3 Scheme of the basic cases for fractional factor analysis

\begin{tabular}{ccccccccc}
\hline Number & $\theta$ & $V_{f}$ & $V_{c}$ & $a_{c}$ & $\alpha_{t}$ & $r_{t}$ & $\begin{array}{c}\text { Surface roughness } \\
R_{a}(\mu \mathrm{m})\end{array}$ & $\begin{array}{c}\text { Subsurface damage } \\
\text { depth }\end{array}$ \\
\hline 1 & -1 & -1 & -1 & 1 & 1 & 1 & 5.2 & 20 \\
2 & 1 & -1 & -1 & -1 & -1 & 1 & 4.8 & 19 \\
3 & -1 & 1 & -1 & -1 & 1 & -1 & 5.3 & 20 \\
4 & 1 & 1 & -1 & 1 & -1 & -1 & 4.5 & 19 \\
5 & -1 & -1 & 1 & 1 & -1 & -1 & 3.1 & 12 \\
6 & 1 & -1 & 1 & -1 & 1 & -1 & 5.5 & 22 \\
7 & -1 & 1 & 1 & -1 & -1 & 1 & 3.5 & 14 \\
8 & 1 & 1 & 1 & 1 & 1 & 1 & 6.8 & 27 \\
9 & 0 & 0 & 0 & 0 & 0 & 0 & 4.9 & 20 \\
10 & 0 & 0 & 0 & 0 & 0 & 0 & 5.4 & 20 \\
11 & 0 & 0 & 0 & 0 & 0 & 0 & 4.7 & 18 \\
12 & 0 & 0 & 0 & 0 & 0 & 0 & 4.5 & \\
\hline
\end{tabular}

Table 4 Results of the analysis of variance for surface roughness

\begin{tabular}{cccccc}
\hline Machining parameters & $\begin{array}{c}\text { Sum of } \\
\text { squares }\left(S S_{B}\right)\end{array}$ & $\begin{array}{c}\text { Degrees of } \\
\text { freedom }\end{array}$ & $\begin{array}{c}\text { Mean square } \\
\left(M S_{B}\right)\end{array}$ & F-value & p-value \\
\hline Fiber orientation angle $(\theta)$ & 9.46 & 2 & 4.73 & 3.63 & 0.000 \\
Cutting speed $\left(V_{c}\right)$ & 5.66 & 2 & 2.83 & 2.17 & 0.000 \\
Depth of cut $\left(a_{c}\right)$ & 4.94 & 2 & 2.47 & 1.90 & 0.000 \\
Edge radius $\left(r_{t}\right)$ & 3.82 & 2 & 1.91 & 1.46 & 0.000 \\
Rake angle $\left(\alpha_{t}\right)$ & 3.12 & 2 & 1.56 & 1.20 & 0.000 \\
Fiber volume fraction $\left(V_{f}\right)$ & 2.24 & 2 & 1.12 & 0.86 & 0.001 \\
Interaction $\left(\theta \times V_{c}\right)$ & 1.6 & 2 & 0.80 & 0.62 & 0.002 \\
Interaction $\left(\theta \times a_{c}\right)$ & 1.22 & 2 & 0.61 & 0.47 & 0.002 \\
Interaction $\left(V_{c} \times a_{c}\right)$ & 0.6 & 2 & 0.30 & 0.31 & 0.002 \\
\hline
\end{tabular}


Table 5 Results of the analysis of variance for subsurface damage depth

\begin{tabular}{cccccc}
\hline Machining parameters & $\begin{array}{c}\text { Sum of } \\
\text { squares }\left(S S_{B}\right)\end{array}$ & $\begin{array}{c}\text { Degrees of } \\
\text { freedom }\end{array}$ & $\begin{array}{c}\text { Mean square } \\
\left(M S_{B}\right)\end{array}$ & F-value & p-value \\
\hline Fiber orientation angle $(\theta)$ & 10.02 & 2 & 5.01 & 20.33 & 0.000 \\
Edge radius $\left(r_{t}\right)$ & 6.04 & 2 & 3.02 & 12.25 & 0.000 \\
Rake angle $\left(\alpha_{t}\right)$ & 5.77 & 2 & 2.885 & 11.71 & 0.000 \\
Fiber diameter $\left(V_{f}\right)$ & 5.70 & 2 & 2.85 & 11.57 & 0.000 \\
Depth of cut $\left(a_{c}\right)$ & 5.09 & 2 & 2.545 & 10.33 & 0.000 \\
Cutting speed $\left(V_{c}\right)$ & 4.68 & 2 & 2.34 & 9.49 & 0.000 \\
Interaction $\left(\theta \times r_{t}\right)$ & 3.83 & 2 & 1.915 & 7.77 & 0.000 \\
Interaction $\left(\theta \times \alpha_{t}\right)$ & 2.03 & 2 & 1.015 & 4.12 & 0.001 \\
Interaction $\left(r_{t} \times \alpha_{t}\right)$ & 1.82 & 2 & 0.91 & 3.7 & 0.002 \\
\hline
\end{tabular}




\section{Figures:}

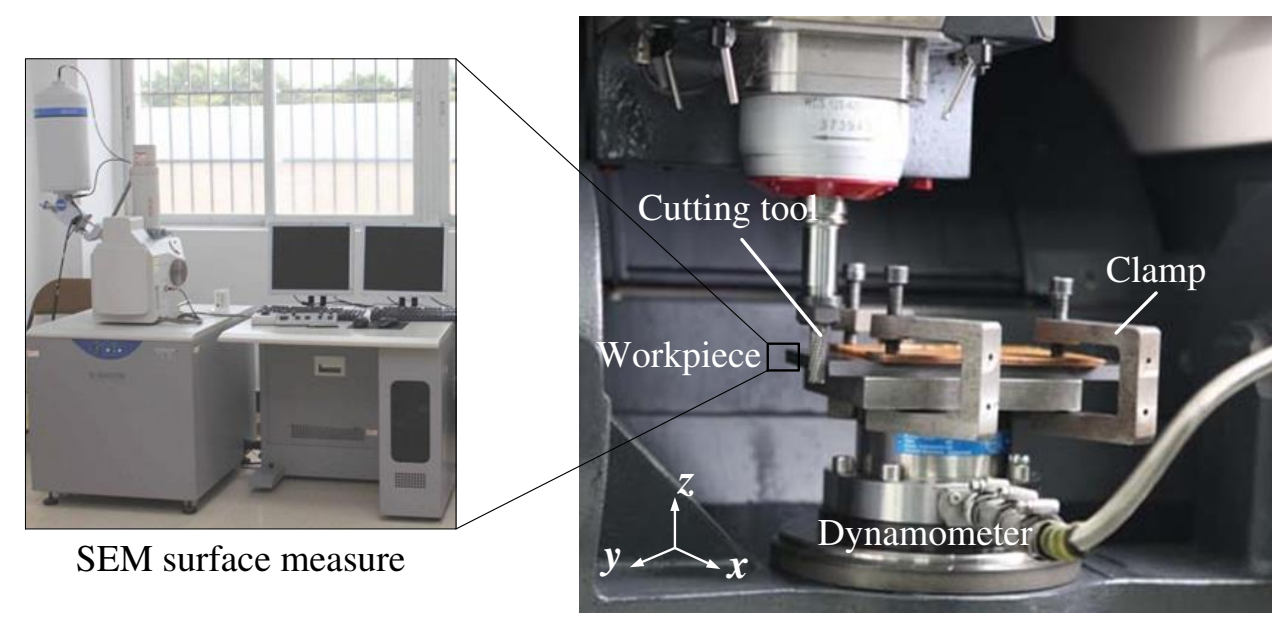

Fig. 1 Experimental setup in CFRP composites trimming

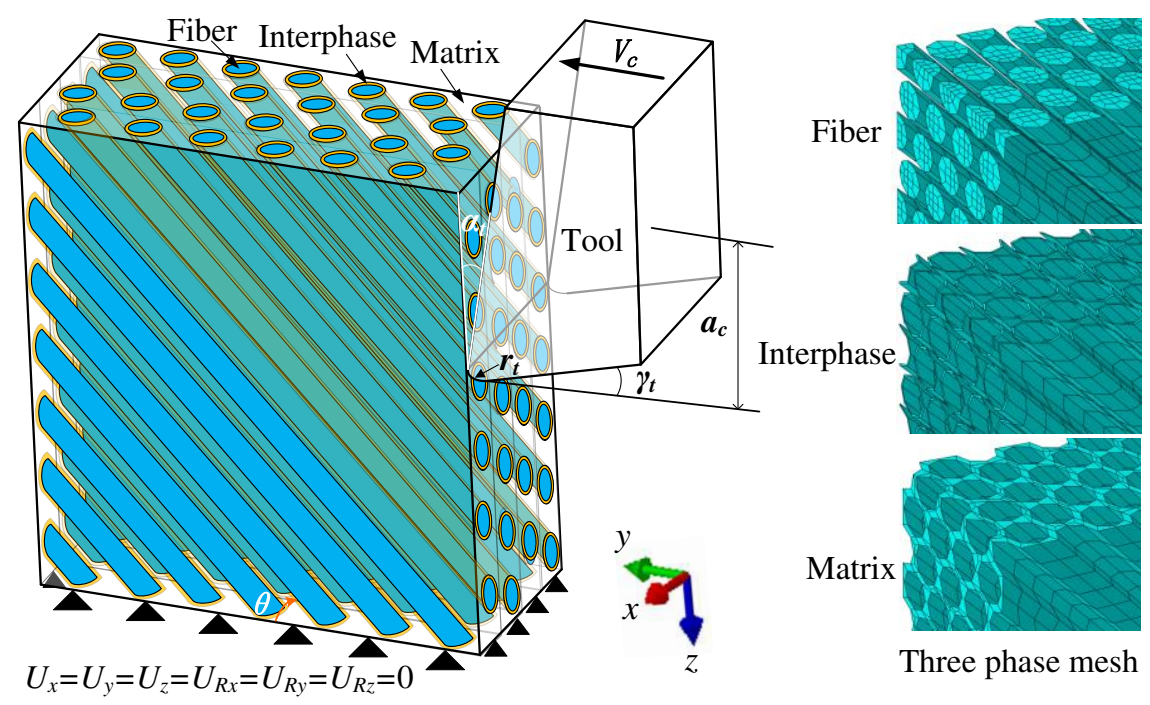

Fig. 2 3D microscopic FE model of orthogonal cutting for CFRP composites $\left(\theta=45^{\circ}\right)$ 


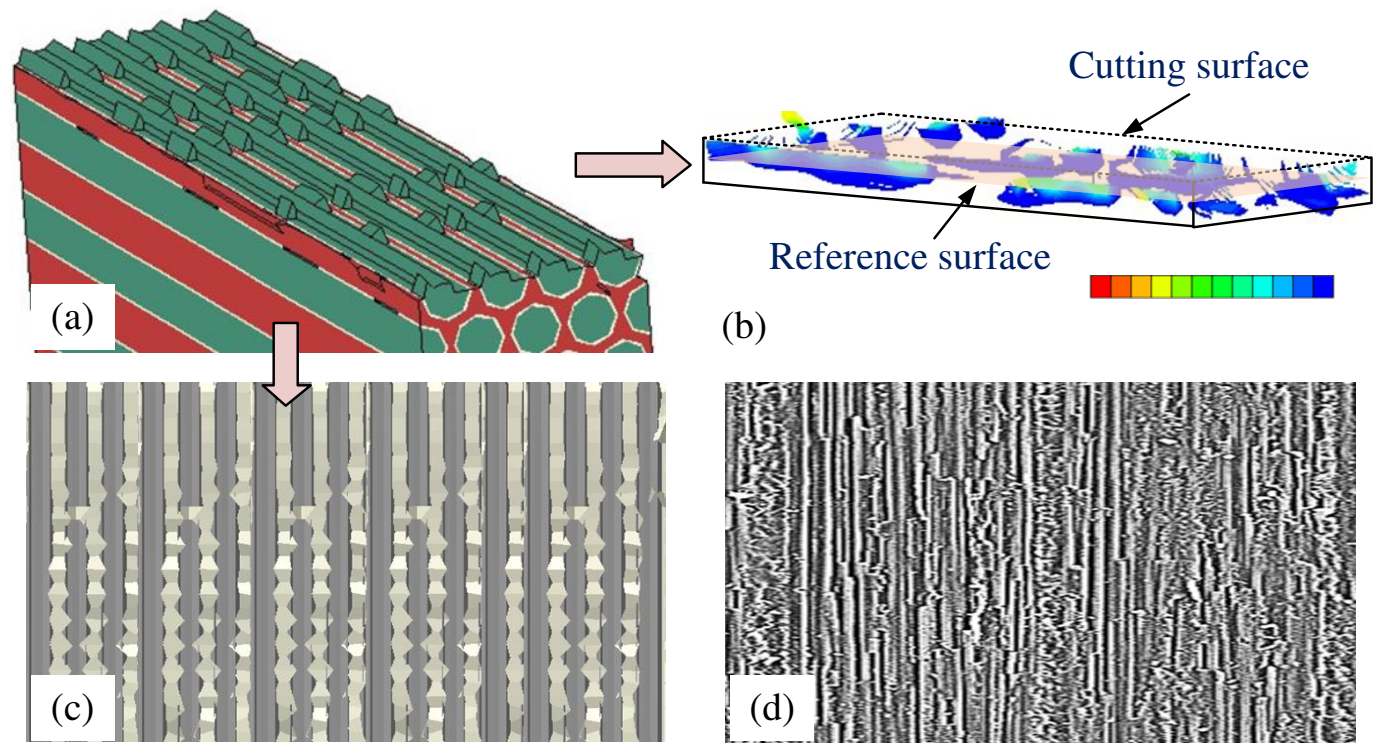

Fig. 3 Simulation results and observation of machined surface at $\theta=0^{\circ}$

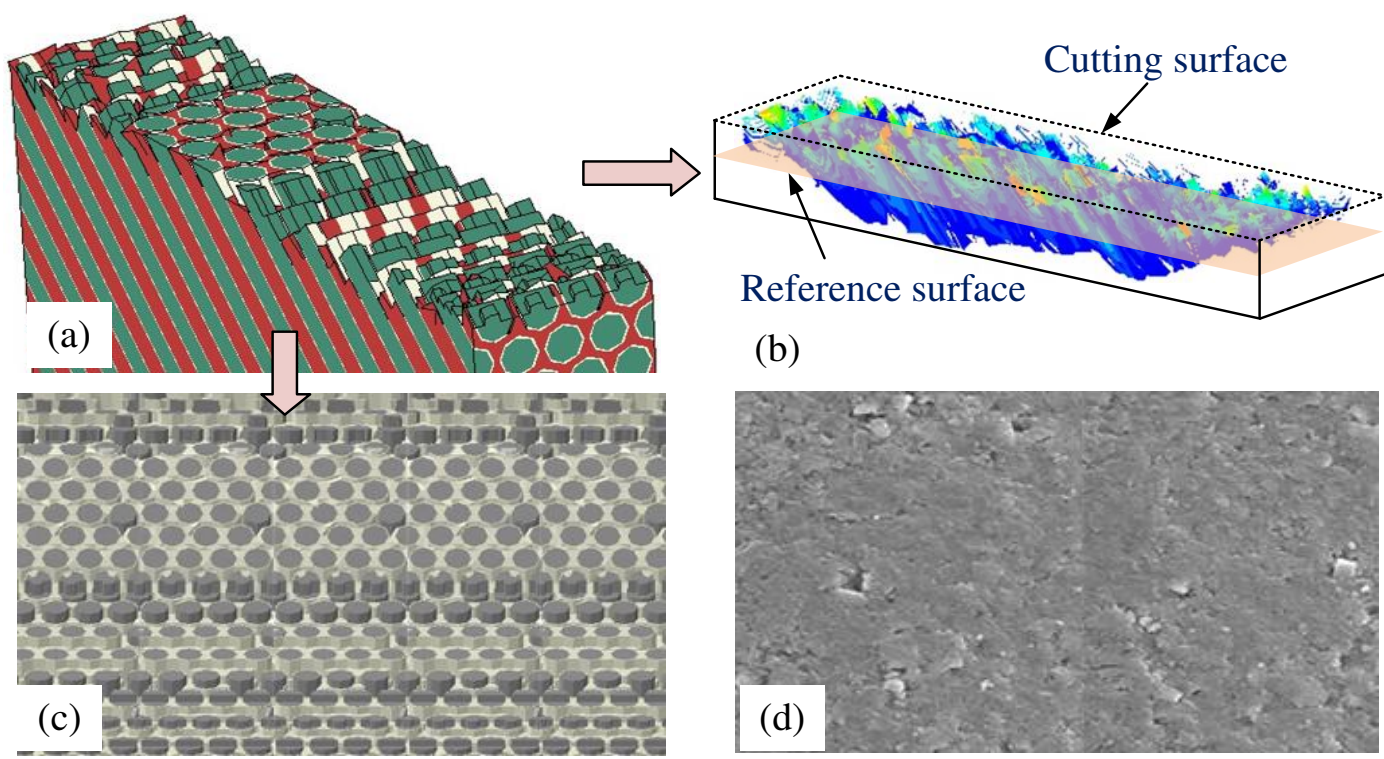

Fig. 4 Simulation results and observation of machined surface at $\theta=45^{\circ}$ 


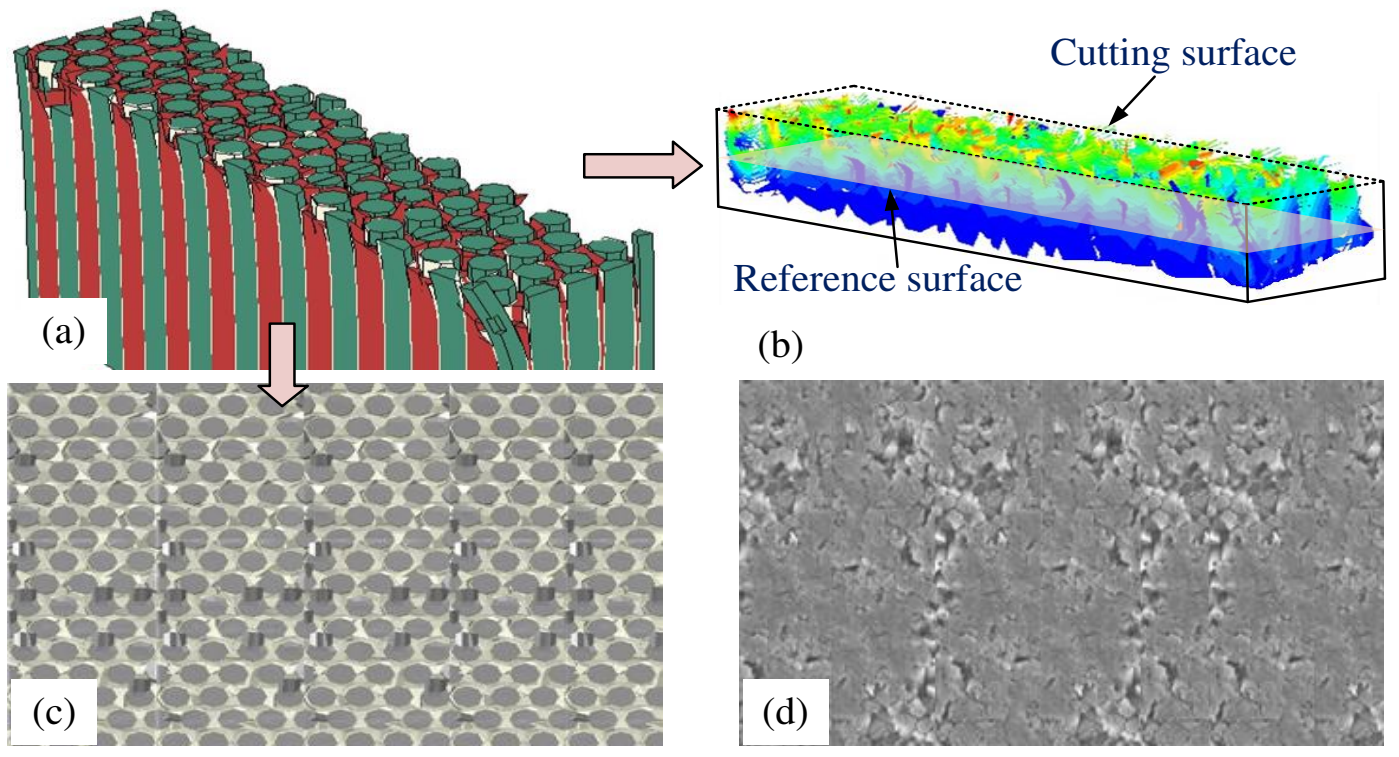

Fig. 5 Simulation results and observation of machined surface at $\theta=90^{\circ}$

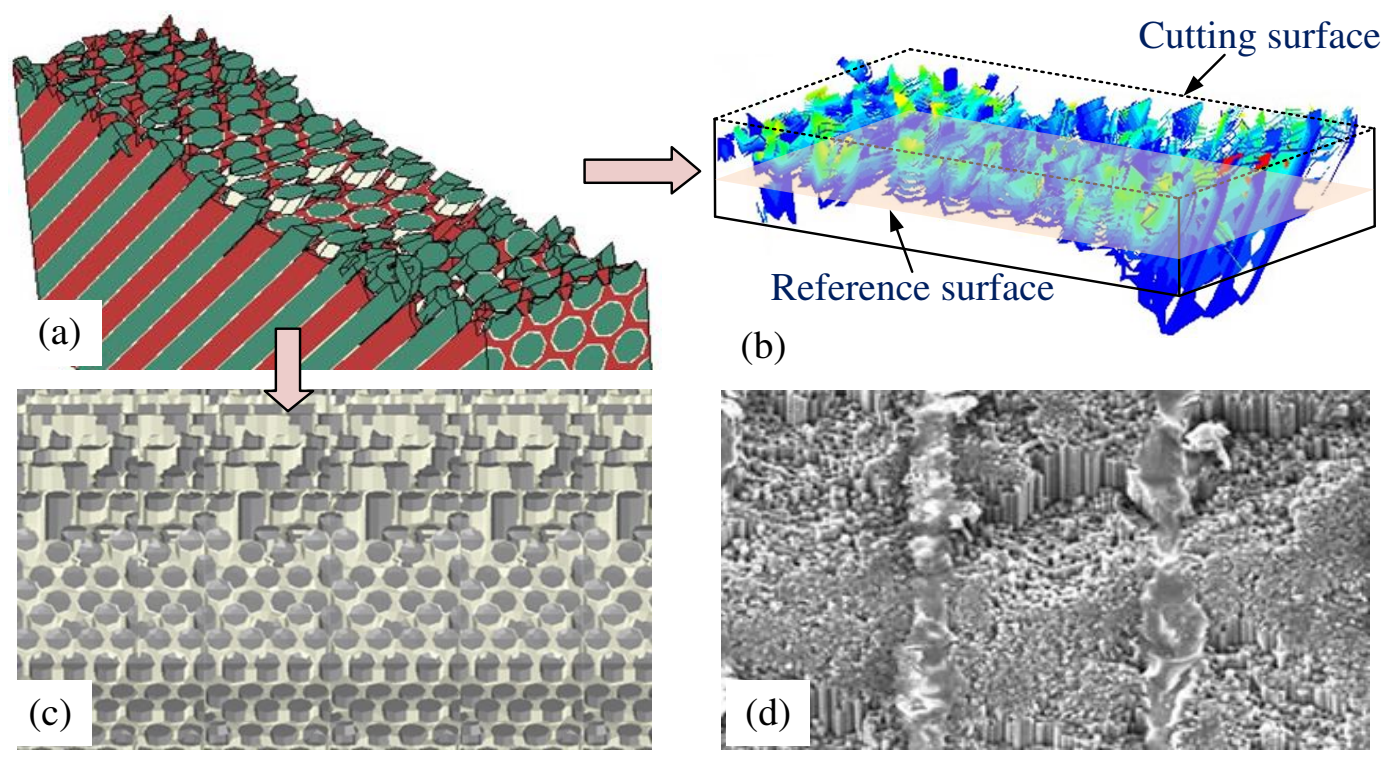

Fig. 6 Simulation results and observation of machined surface at $\theta=135^{\circ}$ 


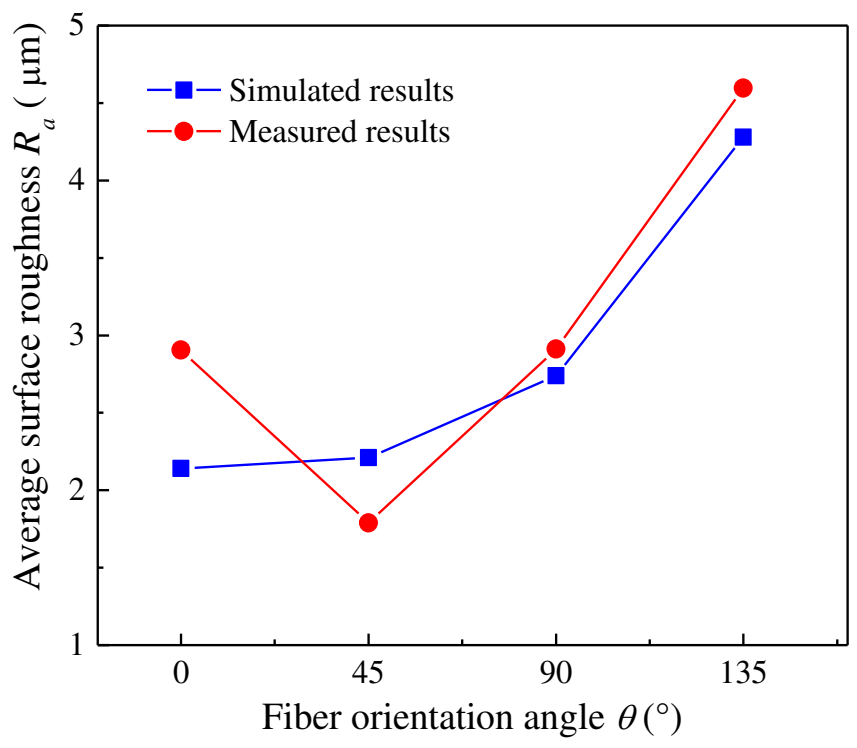

Fig. 7 Comparison of average surface roughness between simulation and measurement for CFRP at different fiber orientations
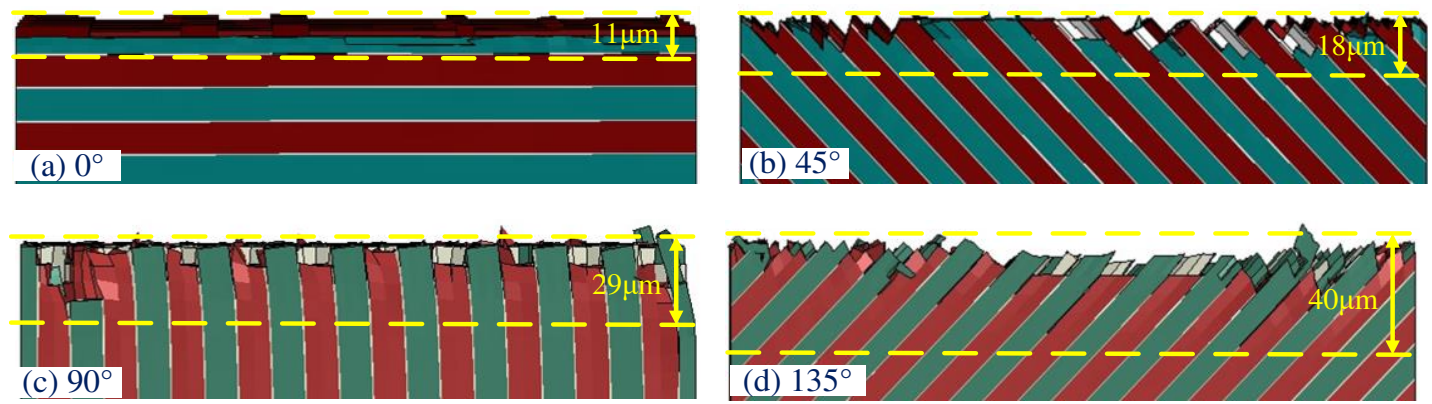

Fig. 8 Depth of subsurface damage in simulation for (a) $0^{\circ}$, (b) $45^{\circ}$, (c) $90^{\circ}$ and (d) $135^{\circ}$ fiber orientation 


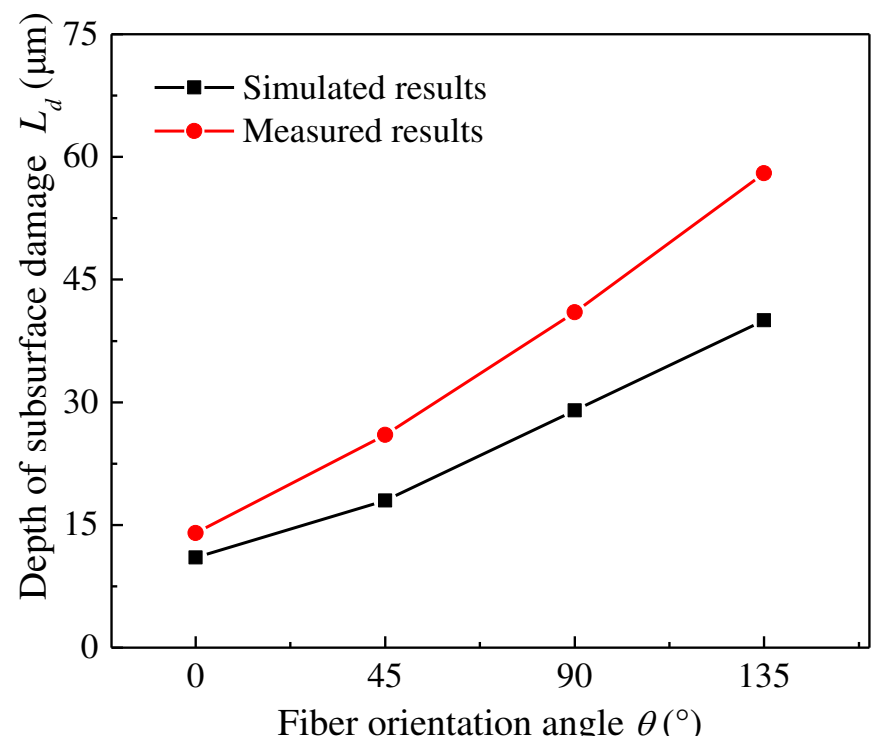

Fig. 9 Comparison of depth of subsurface damage between simulation and measurement for CFRP at different fiber orientations
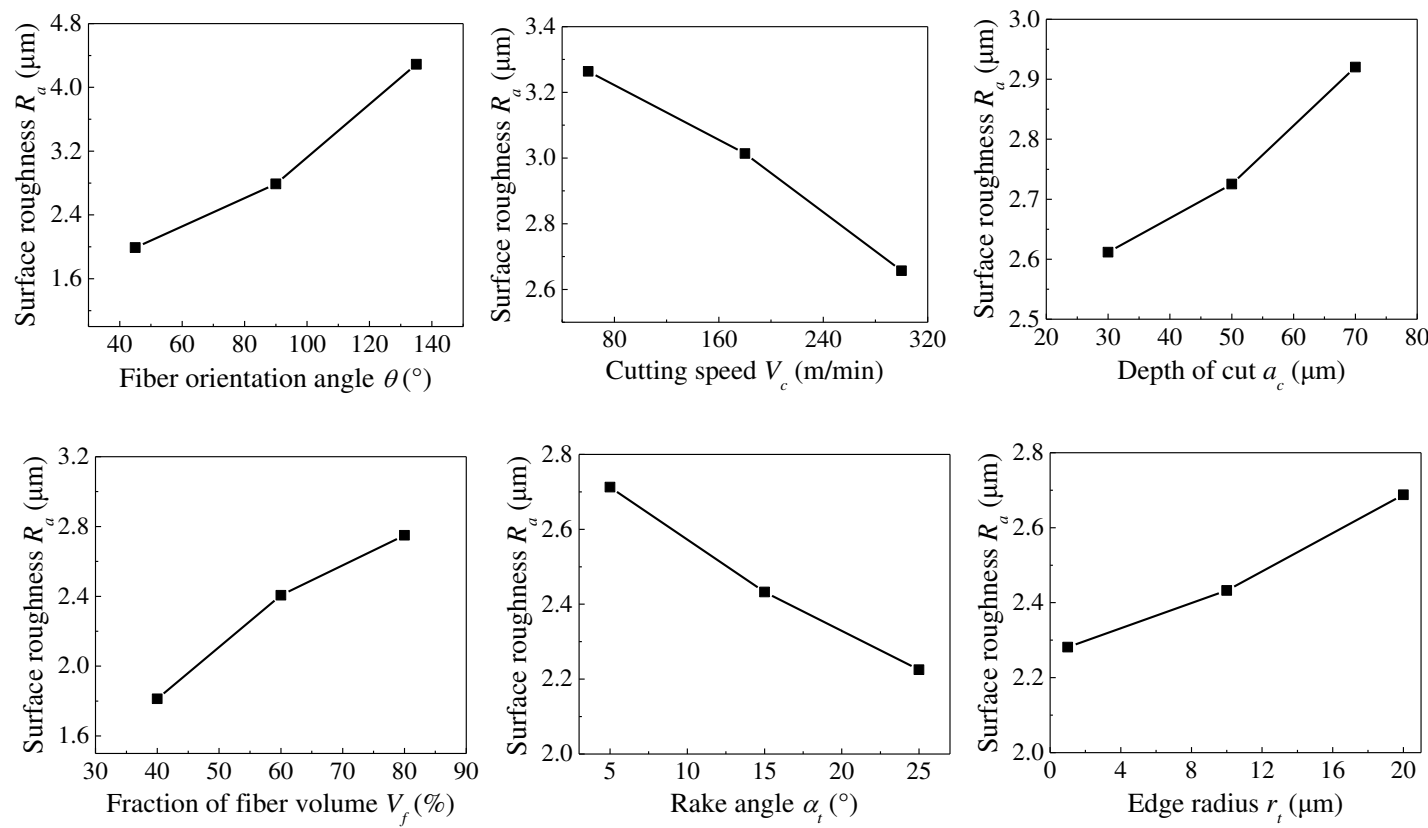

Fig. 10 Dependence of surface roughness on machining parameters 


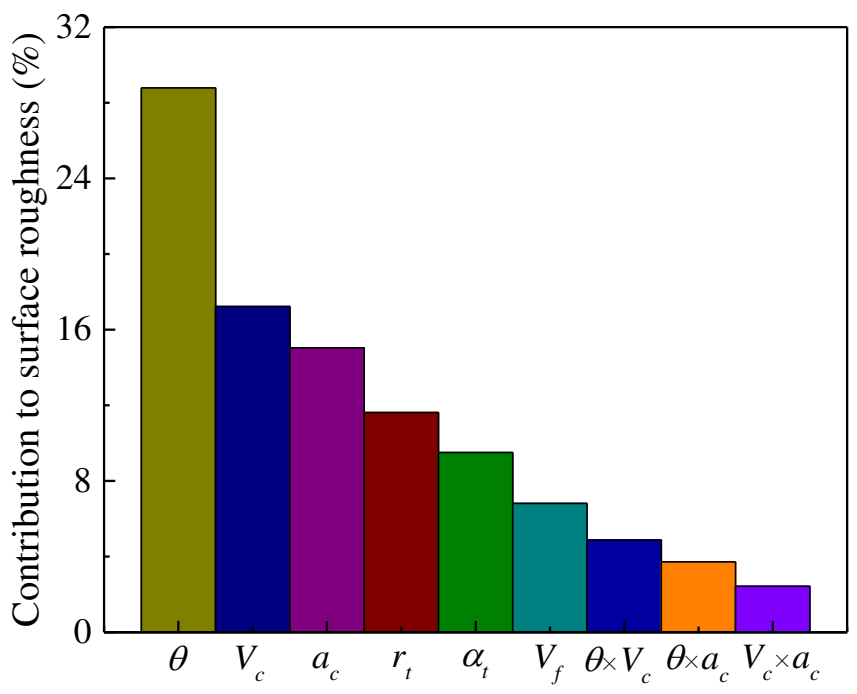

Machining parameters

Fig. 11 Quantitative comparison of the contribution of different machining parameters to surface roughness
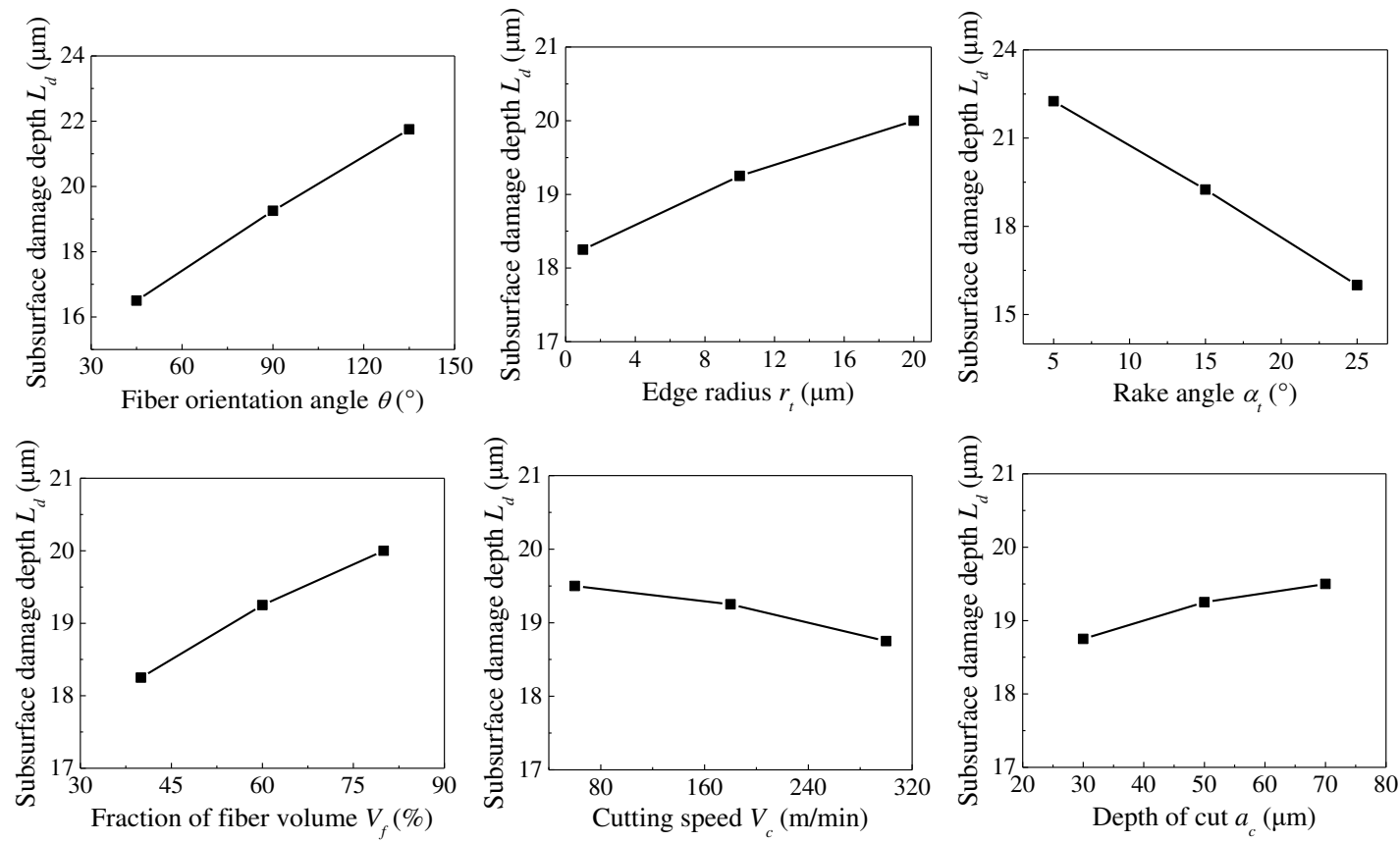

Fig. 12 Dependence of subsurface damage depth on machining parameters 


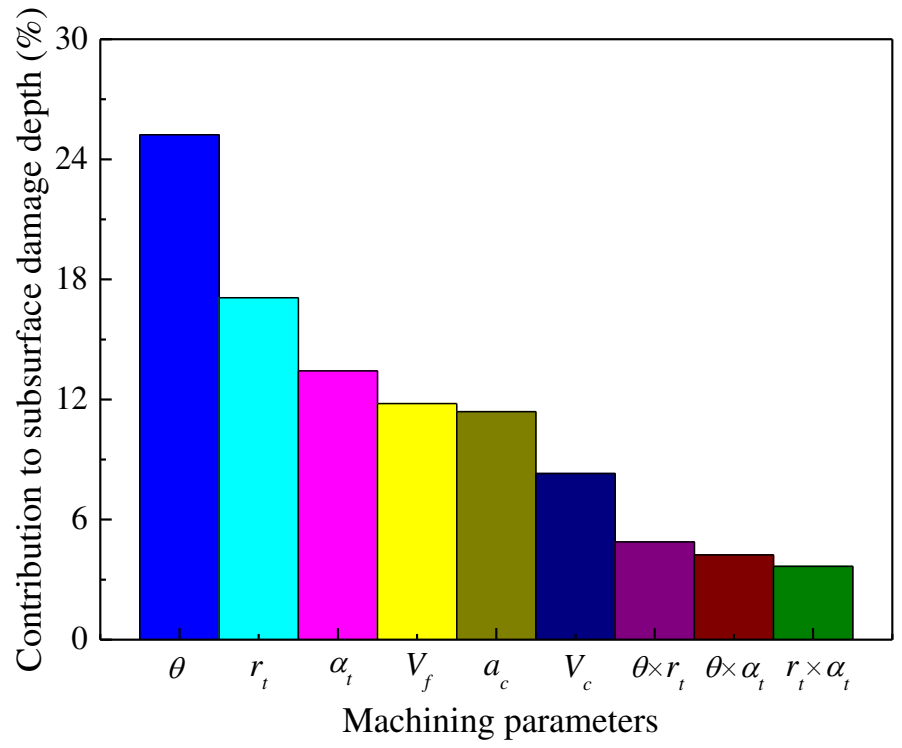

Fig. 13 Quantitative comparison of the contributions of different machining parameters to subsurface damage depth 